\title{
Diş hekimliği öğrencilerinin üst ekstremite antropometrik ölçüleri ve bu ölçülerin laboratuvar başarısı ile ilişkisi
}

\author{
Upper extremity anthropometric measurements of dentistry students and their \\ relationship with laboratory success
}

Danış Aygün, Semih Ekici, Şahika Pınar Akyer

\section{Öz}

Amaç: Diş hekimliği öğrencileri mesleki eğitimlerinin uygulamalı bölümlerinin büyük bir kısmında işlem yapması gayet zor olan cavitas oris bölgesinde çalışmak zorundadırlar. Bu çalışmada, öğrencilerin milimetrik boyutlardaki diş ayrıntılarında yaptıkları girişimlerden aldıkları eğitimlerin değerlendirilmesi aşamasında, öğrenci başarısının öğrencilerin üst ekstremitelerinin antropometrik yapısına bağlı olarak değişip değişmediğinin belirlenmesi amaçlanmıştır.

Gereç ve yöntem: Bu çalışmada Pamukkale Üniversitesi Diş Hekimliği Fakültesi 1. sınıf öğrencilerine girişimsel becerilerin öğretilmesinin ve geliştirilmesinin amaçlandığı "Diş morfolojisi ve manipülasyon" dersinin uygulama sınavından aldıkları başarı puanları ile öğrencilerin üst ekstremitelerinin morfometrik değerlendirilmesi için yapılan antropometrik ölçümlerden oluşan bir grup parametre karşılaştırılmıştır. "Diş morfolojisi ve manipülasyon" dersinin uygulama sınavından aldıkları puanların bu çalışma için seçilmesinin nedeni, bu dersin uygulama çalışmaları sırasında öğrencilerin sabun, mum ve alçı gibi materyaller üzerinde çalışarak gerçek ölçülerde ve/ veya katlı ölçülerde diş yapmalarıdır. Üst ekstremitelerde ölçülen parametreler; brachium, antebrachium ve manus uzunlukları, 1. 2. ve 3. parmakların proksimal, orta ve distal falanksın uzunlukları ve bu falanksların çevre ölçümleridir.

Bulgular: Veriler SPSS 17.0 paket programı kullanılarak analiz edilmiştir. Tanımlayıcı istatistiklerde sayı ve yüzdeler verilmiş olup, kategorik değişkenlerin karşılaştırmasında ki kare testi kullanılmıştır. Öğrencilerin sağ 3. parmak orta falanksın uzunluğunun aynı falanksın çevresine oranı, sol 3. parmak orta falanksın uzunluğunun aynı falanksın çevresine oranı ve sağ 2. parmak proksimal falanksın uzunluğunun aynı falanksın çevresine oranı, sağ üst ekstremitenin uzunluğunun vücut uzunluğuna oranı ile ders başarıları arasında istatistiksel olarak anlamlı bir ilişki olduğu saptanmıştır $(p<0,05)$.

Sonuç: Sonuç olarak elde ettiğimiz falanks uzunluğu ile falanks çevresi oranlamasında, oranları diğer parmaklara göre daha yüksek çıkan, sağ 2. parmak, sağ 3. parmak ve sol 3. parmakların proksimal falanksları daha ince ve uzun olan öğrencilerin uygulamalı derslerde daha başarılı olduğu ortaya çıkmıştır.

Anahtar kelimeler: Antropometri, diş hekimliği, üst ekstremite.

Aygün D, Ekici S, Akyer ŞP. Diş hekimliği öğrencilerinin üst ekstremite antropometrik ölçüleri ve bu ölçülerin laboratuvar başarısı ile ilişkisi. Pam Tıp Derg 2021;14:566-572.

\begin{abstract}
Purpose: Dentistry students have to work in the cavitas oris region, which is very difficult to process in most of the applied parts of their professional education. In this study, it was aimed to determine whether the students' success varies depending on the antropometric structure of the upper extremities of the students at the stage of evaluating the education they received from the interventions made in millimetric tooth details.

Materials and methods: In this study, a group of parameters consisting of anthropometric measurements made for the morphometric evaluation of the Pamukkale University Faculty of Dentistry 1st grade students' upper extremities were compared with the success scores of the practice exam of the "Dental morphology and manipulation" course which aims to teach and develop interventional skills.

The reason why the scores they got from the practice exam of the course "Tooth morphology and manipulation" were chosen for this study is that the students worked on materials such as soap, wax and plaster during the application studies of this course and they made teeth in real size and / or folded sizes. Parameters were measured in the upper extremities; brachium, antebrachium and manus lengths; and proximal, medial and distal phalanx lengths of the 1st, 2nd and 3rd fingers and the circumference measurements of these phalanxes.
\end{abstract}

Danış Aygün, Arş. Gör. Pamukkale Üniversitesi Tıp Fakültesi, Anatomi Anabilim Dalı, Denizli, Türkiye, e-posta: daygun@pau.edu.tr (https:// orcid.org/0000-0002-6165-3422) (Sorumlu Yazar)

Semih Ekici, Doktora Öğrencisi, Pamukkale Üniversitesi Tıp Fakültesi, Anatomi Anabilim Dalı, Denizli, Türkiye, e-posta: ekicisemih@turkdental. net (https://orcid.org/0000-0001-5192-8755)

Şahika Pınar Akyer, Doç. Dr. Pamukkale Üniversitesi Tıp Fakültesi, Anatomi Anabilim Dalı, Denizli, Türkiye, e-posta: spakyer@pau.edu.tr (https://orcid.org/0000-0002-6932-3321) 
Results: The data were analyzed using the SPSS 17.0 package program. Numbers and percentages are given in descriptive statistics, and chi-square test was used for comparison of categorical variables. The statistically significant relationships were found between the lesson success; and ratio of the length of the right 3rd finger medial phalanx to the periphery of the same phalanx; and the ratio of the length of the left 3rd finger medial phalanx to the circumference of the same phalanx; and the ratio of the length of the right 2nd finger proximal phalanx to the circumference of the same phalanx; and the ratio of the length of the right upper limb to the body length $(p<0.05)$.

Conclusion: As a result, in the ratio of phalanx length and phalanx circumference, students whose ratios were higher than other fingers and whose proximal phalanxes of the right 2nd finger, right 3 rd finger and left 3 rd finger were thinner and longer were more successful in practical lessons.

Key words: Anthropometry, dentistry, upper limb.

Aygun D, Ekici S, Akyer SP. Upper extremity anthropometric measurements of dentistry students and their relationship with laboratory success. Pam Med J 2021;14:566-572.

\section{Giriş}

Ülkemizde 2020 yılı verilerine göre 97 diş hekimliği fakültesi bulunmakta ve bu fakültelerden her yıl 6171 yeni öğrenci eğitime başlamaktadır [1]. Bu fakültelerde eğitim almaya hak kazanan öğrenciler üniversite sınavlarında yüksek puan almış, çalışkan ve zeki öğrencilerdir. Çalışkan ve zeki olmanın yanı sıra mesleki eğitimlerini alırken diş hekimliği fakültelerindeki derslerin uygulamalı kısımlarından aldıkları sınav puanları da öğrenci başarılarını belirlemektedir. Uygulamalı derslerdeki öğrenci başarısında, öğrencilerin üst ekstremitelerinin antropometrik yapısı etkili olabilir. Çünkü bu öğrenciler, eğitimleri sırasında aldıkları pek çok dersin uygulamalı kısımlarında işlem yapması gayet zor olan cavitas oris'de çalışmak zorundadırlar. Cavitas oris'in, vestibulum oris ve cavitas oris propria olarak tanımlanan iki bölümü vardır. Vestibulum oris, ön ve daha dış tarafta bulunan dar bölüm olup sınırlarını önden dudaklar ve rima oris, yanlardan yanaklar, arka ve iç taraftan ise diş arkusları oluşturur. Cavitas oris propria ise vestibulum oris'in arkasında bulunan daha büyük bir boşluktur ve sınırlarını dışardan diş arkusları, üstten damak, alttan ağız tabanı ve arkadan da isthmus faucium adlı bir geçit oluşturur. Vestibulum oris ile cavitas oris propria'yı birbirinden ayıran yapılar diş arkuslarıdır. Bunlara üstte arcus alveolaris superior, altta ise arcus alveolaris inferior adı verilir [2]. Yetişkin bir insanda 16 alt, 16 üst çenede olmak üzere 32 diş vardır. Dişlerin boyutları milimetrelerle ölçülür, örneğin ön kesici dişlerin boy uzunlukları 10,4-11,2 mm genişlikleri ise 8,73-9,3 mm'dir [3]. Bu değerler düşünüldüğünde, bu boşlukların ve içindeki yapıların ne kadar küçük oldukları ve bu alanda çalışmanın ne kadar zor olduğu anlaşıımaktadır.

$\mathrm{Bu}$ çalışmada, Pamukkale Üniversitesi Diş Hekimliği Fakültesi 1. sınıf öğrencilerinin başarılarının değerlendirilmesinde girişimsel becerilerinin etkili olduğu "Diş morfolojisi ve manipülasyon" dersinin uygulama sınavından aldıkları başarı puanları ile öğrencilerin üst ekstremitelerinde belirlenen morfometrik ölçümlerden oluşan parametreler birlikte değerlendirilerek; öğrencilerin üst ekstremitelerinin antropometrik yapılarının uygulamalı derslerdeki başarılarında etkili olup olmadığının belirlenmesi amaçlanmıştır.

\section{Gereç ve yöntem}

Çalışma, kesitsel tipte bir araştırmadır. Çalışma evreni 2018-2019 eğitim öğretim yılı Pamukkale Üniversitesi Diş Hekimliği Fakültesi dönem 1 öğrencilerinden oluşmaktadır. Toplam 93 öğrenci vardırveörneklem hesabı yapılmadan tüm öğrencilere ulaşılması planlanmıştır.

Verilerde kullandığımız ders başarı puanları, öğrencilerin "Diş morfolojisi ve manipülasyon" dersi uygulama sınavında aldıkları puanlardır. Morfometrik ölçümler ise dijital kaliper, dijital tartı ve mezura kullanılarak aynı kişi tarafından üçer kere yapılmış ve sonra ortalamaları alınmıştır (Şekil 1). Dijital kaliper kullanımı metakarpofalengeal eklemler başta olmak üzere ekstremite morfometrik ölçümlerinde kullanılmaktadır [4]. Üst ekstremitelerde belirlenen morfometrik ölçümler; brachium, antebrachium ve manus uzunlukları, 1. 2. ve 3. parmakların proksimal, orta ve distal falanks uzunlukları ve bunların çevreleridir. Bu 
parametrelerde ölçülmesi için ilk 3 parmağın seçilmesinin nedeni uygulama çalışmaları esnasında öğrencilerin bu parmakları kullanmasıdır (Şekil 2, Şekil 3).

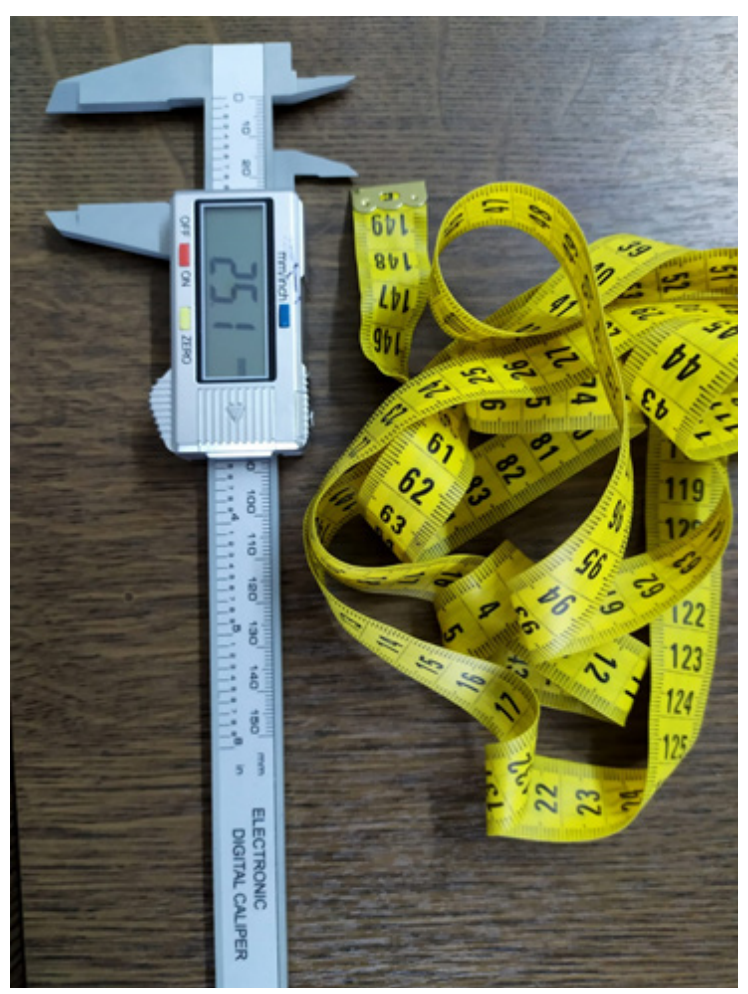

Şekil 1. Dijital kaliper ve mezura

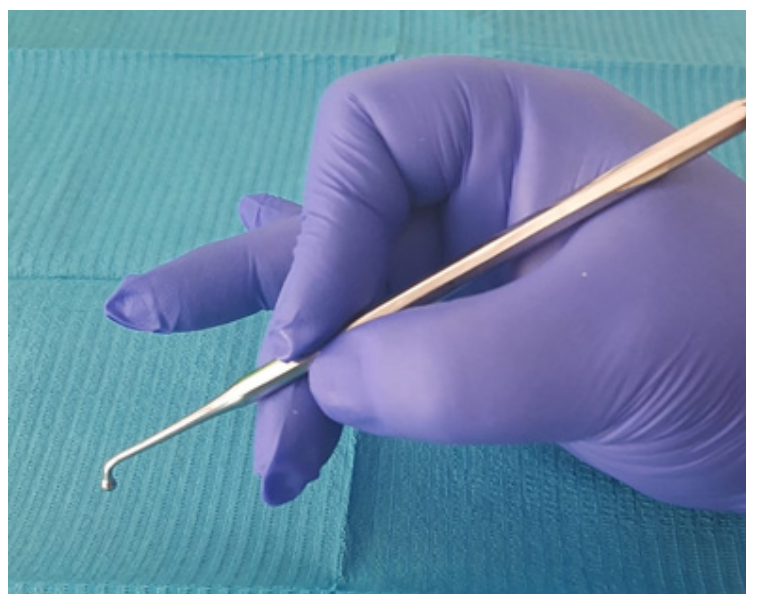

Şekil 2. Diş hekimi aparat tutma tekniği

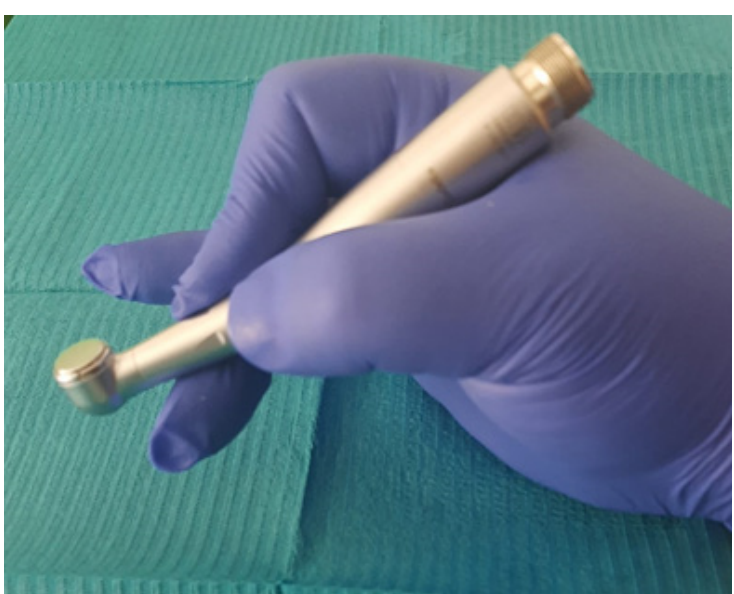

Şekil 3. Diş hekimi aparat tutma tekniği

Brachium uzunluğu, proksimalde tuberculum majus ile distalde olecranon arasındaki mesafeyi, antebrachium uzunluğu olecranon ile processus styloideus ulnae ve processus styloideus radiii arasındaki mesafeyi tanımlamaktadır. Proksimal falanksın uzunluğu metacarpophalangeal eklem ile proksimal interphalangeal eklem arasındaki mesafeyi, orta falanksın uzunluğu proksimal interphalangeal eklem ile distal interphalangeal eklem arasındaki mesafeyi, distal falanksın uzunluğu distal interphalangeal eklem ile parmak ucu arasındaki mesafeyi tanımlamaktadır. El uzunluğu el bileğinin orta noktasının 3. parmağın distal falanksının uç kısmına olan mesafe ölçülerek bulunmuştur. (Şekil 4, Şekil 5) falanksların çevreleri ise falanksların tam orta noktalarından mezura ile ölçülmüştür. Üç boyutlu olarak düşünüldüğünde falanksların yapılarını değerlendirebilmek amacıyla, ölçümlerle elde edilen uzunluk ve çevre ölçüm değerlerinin birbirlerine oranları hesaplandı ve ortaya çıkan değerler istatistiksel olarak değerlendirildi ve istatistiksel olarak anlamlı olanları belirlendi.

Baskın el kullanımını tespit etmek için de Geschwind skorlaması kullanılmıştır (Tablo 1). Bu skorlamada kişi sorulan eylemi hangi eli ile yapıyor ise onu işaretlemekte ve $+/-10$ puanı verilerek skoru hesaplanmaktadır. 


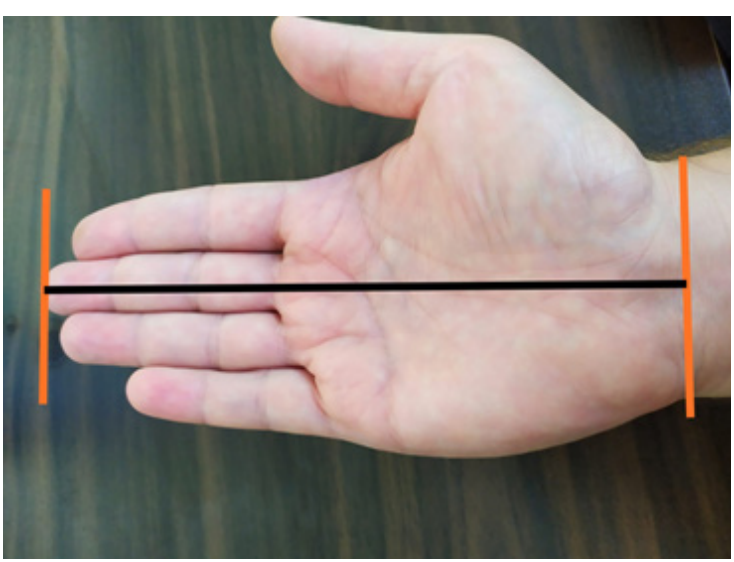

Şekil 4. Ölçüm örneği-el

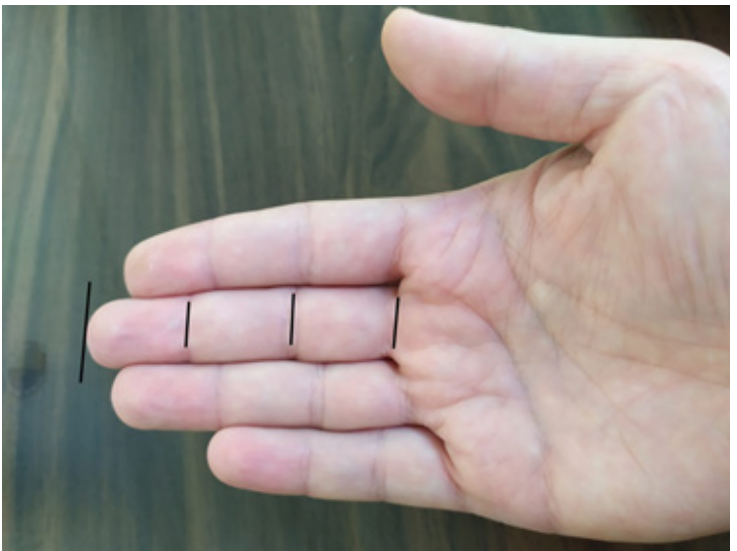

Şekil 5. Ölçüm örneği-falankslar

Tablo 1. Geschwind skorlama

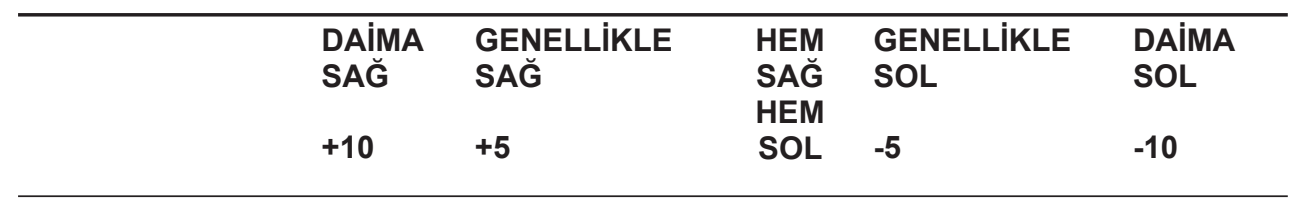

1.Yazı yazma

2.Resim yapma

3.Taş atma

4.Makas tutma

5.Diş fırçalama

6.Bıçak tutma

7.Çatal tutma

8.Çekiç/küreksapı

tutma (alttaki el)

9.Kibrit çakan el

(çöpü tutan el)

10.Kutu.kapağı

açma

Veriler SPSS 17.0 paket programı kullanılarak analiz edilmiştir. Tanımlayıcı istatistiklerde sayı ve yüzdeler verilmiş olup, kategorik değişkenlerin karşılaştırmasında ki kare testi kullanılmıştır. $P<0,05$ anlamlı olarak kabul edilmiştir.

Çalışma için Pamukkale Üniversitesi Girişimsel Olmayan Klinik Araştırmalar Etik Kurulu'nun 23.01.2019 tarih ve 5389 sayısı ile etik kurul izni ve katılımcılardan sözlü onam alınmıştır.

\section{Bulgular}

Veriler 2018-2019 eğitim öğretim yılının ilk anatomi dersinde toplanmış olup, 17 kişinin çalışmaya katılmayı kabul etmemesi nedeniyle toplam 76 kişiye ulaşılmıştır. Ulaşılabilirlik hızı $\% 81,7$ olarak hesaplanmıştır. Diş hekimliği öğrencilerinin \%82'sine ulaşılıp ölçümler yapıldı. Öğrencilerin \%42'si erkek, \%58'i kadındı. Geschwind skorlamasının sonucunda \%89 oranında sağ el kullanımı, \%11 oranında da sol el kullanımı tespit edilmiştir. 3 farklı diş modelinin yapıımasına bağlı verilen uygulama puanlarında öğrencilerin sadece $\% 7,8$ 'i tüm uygulamalarda 
başarılı olmuştur. Maksiller kanin diş yapımı uygulamasında öğrencilerin $\% 25$ 'i, üst molar 1 diş uygulamasında \%44,7'si, alt molar 2 diş uygulamasında \%68,4'ü başarılı olmuştur ve alt molar 2. diş uygulamasındaki başarı en fazladır (Tablo 2). Baskın el kullanma durumu ile ders başarısı arasında ise istatistiksel olarak anlamlı ilişki saptanmamıştır.

Öğrencilerin sağ 3. parmak orta falanksın uzunluğunun aynı falanksın çevresine oranı, sol 3. parmak me orta falanksın uzunluğunun aynı falanksın çevresine oranı ve sağ 2 . parmak proksimal falanksın uzunluğunun aynı falanksın çevresine oranı, sağ üst ekstremitenin uzunluğunun vücut uzunluğuna oranı ile ders başarıları arasında anlamlı ilişki saptanmıştır $(p<0,05)$ (Tablo 3). Öğrencilerin diğer ölçümleri ile ders başarıları arasında istatistiksel olarak anlamlı bir ilişki saptanmamıştır.

Buna göre diş hekimliği öğrencilerinde sağ el 2. parmak proksimal falanksların ve her iki elde 3. parmak orta falanksların boy/çevre oranının yüksek olması ile uygulamalı ders başarısının arttığı gözlenmiştir.

Tablo 2. Ders başarı yüzdeleri

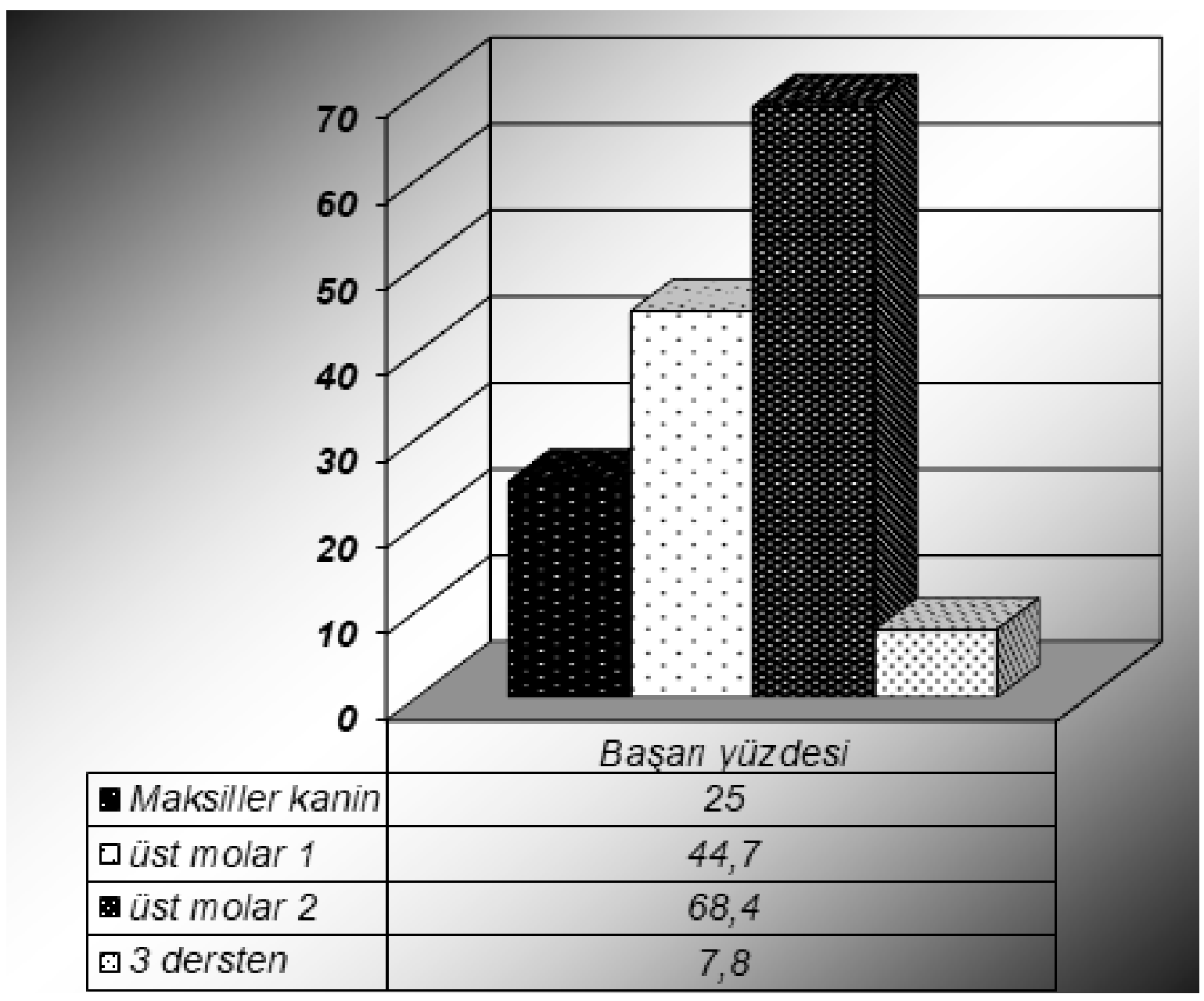


Tablo 3. Ders başarısına etki eden ölçümler

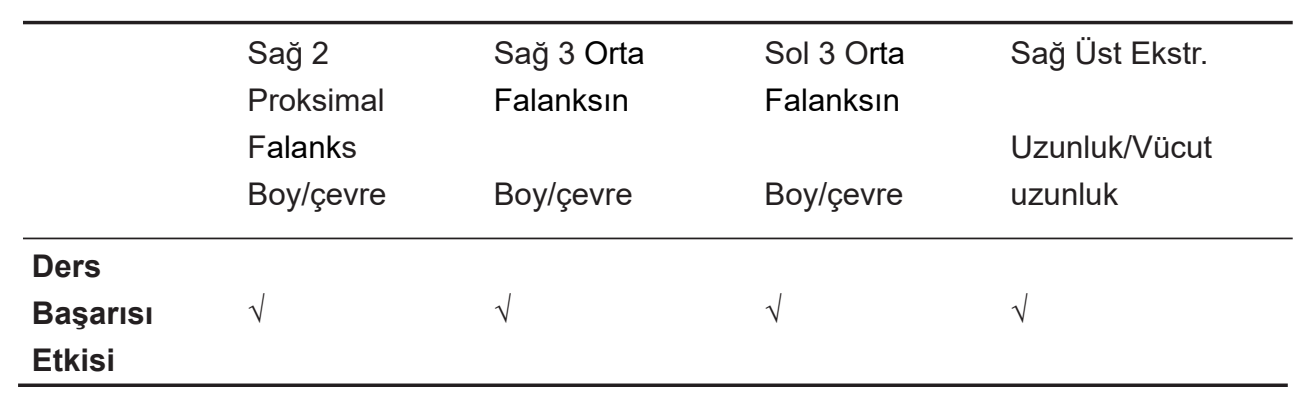

\section{Tartışma}

Verilerde kullandığımız ders notlarının, "Diş morfolojisi ve manipülasyon" dersi uygulama notları olmasının sebebi, bu dersin uygulamasında öğrencilerin sabun, mum ve alçı gibi materyaller üzerinde çalışarak gerçek ölçülerde ve/veya katlı ölçülerde diş yapmalarıdır. Bu çalışmada 3 farklı dişin ayrıntılı olarak sabun kullanılarak yapılmasına göre verilen uygulama sonu başarı puanları esas alınmıştır. Bunlar üst 1. molar (dens molaris), molar dişlerin en büyüğüdür. Alt 2. molar (dens molaris), 1. molar'den daha küçüktür. Maxiller kanin (dens caninus), anterior- posterior diş geçişinde olandır. Morfometrik ölçümler birçok faktöre göre değişiklik göstermektedir ve bu çalışma şartlarını da etkilemektedir [5].

Parmak oranlarının ölçülmesiyle ilgili yapılan bazı çalışmalarda sağ el ile sayısal ve eşit ağırlık seçiminde anlamlı ilişki olduğu görülmektedir [6]. Bazı çalışmalarda ortalama indeks ve yüzük parmak uzunluğu oranının her iki el için erkeklerde anlamlı olarak yüksek çıkmıştır [7]. Bazı çalışmalarda cinsiyete göre mutlak parmak uzunlukları çeşitlilik göstermektedir ve bu etnik olarak da değişkenlik göstermektedir [8]. Bizim çalışmamızda cinsiyete göre ayrı ölçüm yapılmamıştır.

Sporcular üzerinde yapılan bir çalışmada 2D:4D parmak uzunluğu oranının düşük olduğu erkeklerde birçok spor dalında başarı oranının ve görsel uzaysal yeteneğin yüksek olduğu bildirilmiştir [9]. Diğer bir çalışmada da 2D: 4D oranı ile spor başarısı arasındaki anlamlı ilişki kadınlarda ve erkeklerde aynı olarak bildirilmiştir [10].

El genişliği ve el uzunluğu ile ilgili yapılan başka bir çalışmada da boy uzunluğu ile korelasyonu araştırılmıştır, araştırmanın korelasyon matrisi bu iki ölçüm arasındaki ilişkinin yakın benzerliğini göstermektedir [11].

Yaptığımız çalışmada baskın el kullanımı ile ders başarısı arasında ilişki saptanmamıştır fakat literatürde erkeklerde baskın el sağlaklık olduğunda el becerisinin arttığını gösteren çalışma vardır [12].

Sonuç olarak öğrencilerin sağ 2. parmak proksimal falanksın uzunluğunun aynı falanksın çevresine oranı, sağ 3. parmak m orta falanksın uzunluğunun aynı falanksın çevresine oranı, sol 3. parmak orta falanksın uzunluğunun aynı falanksın çevresine oranı ve sağ üst ekstremitenin uzunluğunun vücut uzunluğuna oranı ile ders başarılarında istatistiksel olarak anlamlı fark bulunmuştur $(p<0,05)$. Buna göre elde ettiğimiz falanks uzunluğu ile falanks çevresi oranlamasında, oranları diğer parmaklara göre daha yüksek çıkan, sağ 2 . parmak, sağ 3. parmak ve sol 3. parmakların proksimal falanksları daha ince ve uzun olan öğrencilerin uygulamalı derslerde daha başarılı olduğu ortaya çıkmıştır.

Çıkar ilişkisi: Yazarlar çıkar ilişkisi olmadığını beyan eder.

\section{Kaynaklar}

1. Dişhekimliğinde insan gücü planlaması. Türk Dişhekimleri Birliği Yayınları. 2020:6. Erişim adresi: http://tdb.org.tr/tdb/v2/ekler/Dishekimliginde_ Insangucu_Planlamasi_2020.pdf. Erişim tarihi Ağustos 2020

2. Arıncı K, Elhan A. Anatomi: kemikler, eklemler, kaslar, iç organlar. 1.Cilt, 5.Baskı, Kemikler; s.14. Ankara, Güneş Tıp Kitabevleri 2014.

3. Brandão RCB, Brandão LBC. Finishing procedures in Orthodontics: dental dimensions and proportions (microesthetics). Dental Press J Orthod 2013;18:147174. Available at: https://www.scielo.br/pdf/dpjo/ v18n5/06.pdf. Accepted August 30, 2013 
4. Butler MG, Meaney FJ, Kaler SG. Metacarpophalangeal pattern profile analysis in clinical genetics: an applied anthropometric method. Am J Phys Anthropol 1986;70:195-201. https://doi.org/10.1002/ ajpa. 1330700206

5. Uşan Ş, Oğulata S. İlköğretim okullarının ergonomik açıdan değerlendirilmesi ve yeniden düzenlenmesi: Çukurova bölgesindeki uygulamalar. ÇÜ Fen ve Mühendislik Bilimleri Dergisi 2013;29:99-109.

6. Cebe B, Varol A. (2D: 4D)Parmak uzunlukları oranı ile kişilerin sayısal-sözel dallara yatkınlıkları arasındaki ilişkinin uzman sistem ile tespiti. Türkiye Bilişim Vakfı Bilgisayar Bilimleri ve Mühendisliği Dergisi 2012:6. Erişim adresi: https://dergipark.org.tr/tr/pub/tbbmd/ issue/22246/238810. Erişim tarihi 15 Eylül 2020

7. Gupta S, Gupta V, Tyagi N, et al. Index/ring finger ratio, hand and foot index: gender estimation tools. J Clin Diagn Res (JCDR) 2017;11:73-77. https://doi. org/10.7860/JCDR/2017/25807.10084

8. Khaled $E A H$, Soheir AM, Maha $A H$, Eman AM, Determination of sex from hand dimensions and index/ ring finger length ratio in Upper Egyptians. Egyptian $\mathrm{J}$ Forensic Sci 2011;1:80-86. https://doi.org/10.1016/j. ejfs.2011.03.001

9. Manning JT, Taylor RP. Second to fourth digit ratio and male ability in sport: implications for sexual selection in humans. Evol Hum Behav 2001;22:61-69. https://doi. org/10.1016/s1090-5138(00)00063-5

10. Tester N, Campbell A. Sporting achievement: what is the contribution of digit ratio? J Pers 2007;75:663-678. https://doi.org/10.1111/j.1467-6494.2007.00452.x

11. Abdel Malek AK, Ahmed AM, el-Sharkawi SA, el-Hamid NA. Prediction of stature from hand measurements. Forensic Sci Int 1990;46:181-187. https://doi. org/10.1016/0379-0738(90)90304-h

12. Öztaşan N, Kutlu N. Sağlıklı bireylerde parmak uzunluk oranlarının (2d: $4 d$ ); el tercihi, nonverbal zeka, görsel, işitsel ve verbal yetenekler, motor beceri ve serebral lateralizasyon ile ilişkisi. Balıkesir Sağlık Bil Derg 2014;3:11-15. https://doi.org/10.5505/ bsbd.2014.02886

Teşekkür: Çalışmanın yapılmasına katılan Pamukkale Üniversitesi Diş Hekimliği Fakültesi dönem 1 öğrencilerimize teşekkür ederiz.

*Bu çalışma " 20. Ulusal Anatomi Kongresi, İstanbul, Türkiye, 27-31 Ağustos 2019" kongresinde sözlü sunum olarak sunulmuştur.

Etik kurul onayı: Pamukkale Üniversitesi Girişimsel Olmayan Klinik Araştırmalar Etik Kurulu'nun 23.01.2019 tarih ve 5389 sayısı ile etik onayı alınmıştır.

\section{Yazarların makaleye olan katkıları}

D.A. ve Ş.P.A. çalışmanın ana fikrini ve hipotezini kurgulamışlardır. S.E. teoriyi geliştirmiş, gereç ve yöntem bölümünü düzenlemiş. Sonuçlar kısmındaki verilerin değerlendirmesini S.E. ve D.A. yapmışlardır. Makalenin tartışma bölümü Ş.P.A. ve D.A. tarafından yazılmış, S.E. ve Ş.P.A. gözden geçirip gerekli düzeltmeleri yapmışlar ve onaylamışlardır. Ayrıca tüm yazarlar çalışmanın tamamını tartışmış ve son halini onaylamıştır. 